\title{
A ORTODOXIA E A QUESTÃO DO ABORTO: UM OLHAR NECESSÁRIO
}

\author{
* Silvana Beline Tavares
}

\section{Resumo:}

Considerando-se que a luta heterodoxa por direitos sexuais e reprodutivos tem como um de seus focos o debate em torno da descriminalização do aborto, tem-se por objetivo investigar em que medida os projetos de leis propostos por membros da bancada evangélica tem se colocado como representantes da ortodoxia social, religiosa e jurídica. As categorias de Gênero e Direito são utilizadas como referencial teórico e metodológico para a construção do trabalho a partir da Pesquisa Bibliográfica.

\section{Palavras-chave:}

AbortoGêneroDireitoheterodoxiaOrtodoxia

\section{ORTHODOXY AND THE ISSUE OF ABORTION: A NECESSARY LOOK}

\begin{abstract}
:
Considering that the heterodox struggle for sexual and reproductive rights has as one of its focuses the debate on the decriminalization of abortion, the objective is to investigate to what extent the draft laws proposed by members of the evangelical group have been placed as representatives of social, religious and juridical orthodoxy. The categories of Gender and Law are used as theoretical and methodological reference for the construction of the work from the Bibliographic Research.
\end{abstract}

\section{Keywords:}

AbortionGenderLawheterodoxyOrthodoxy

\section{Introdução}

As feministas desafiaram a prática da exclusão de mulheres da cidadania, com o argumento de que as diferenças de sexo não sinalizavam maior ou menor capacidade social, intelectual e política (SCOTT, 2002). A perspectiva feminista tem buscado a redefinição de um conjunto de direitos humanos no século XXI, pois, "o conceito de direitos humanos não é um conceito estático ou propriedade de um só grupo, mais ainda, seu significado se amplia no tempo em que a cidadania redefine suas necessidades e seus desejos na relação com eles" (FOLGUERA, 2006, p.89). Combinar a crítica às suposições

\footnotetext{
* Doutora em Sociologia pela UNESP/Araraquara, mestre em Sociologia pela Universidade Estadual Paulista Júlio de Mesquita Filho (2002). Graduada em Ciências Jurídicas (2002) e em Ciências Sociais (1989).Atualmente é professora Adjunta no Curso de Direito da Universidade Federal de Goiás. Email:belinesilvana@gmail.com Rua 70, 250, apto 1902, Jardim Goiás, Goiânia/ GO. Email:belinesilvana@gmail.com
} 
do discurso pelos direitos com uma permanente contextualização dos direitos nos sistemas de relações sociais especialmente de gênero seria uma saída estratégica política para fazer a constante adequação de direitos no que se refere às mulheres em suas diversas diferenças (JELIN, 1994, p.126).

Embora nas últimas décadas seja possível notar os avanços sociais e as conquistas em relação às mulheres, a discussão sobre o aborto continua provocando controvérsias até mesmo nos países onde já houve a descriminalização e legalização a partir dos anos de 1970. Discussão extensa e antiga que gera debates polêmicos e complexos envolvendo aspectos religiosos, sociais, morais, éticos, jurídicos que permeiam as convicções pessoais e sociais relativas ao aborto, tem sido retomada com mais afinco a partir dos projetos de lei propostos por membros da bancada evangélica no Congresso Nacional e agora legitimada pelo governo do presidente eleito Jair Bolsonaro.

Necessário lembrar que mesmo com as interdições construídas no campo jurídico pelas forças que lhe dão manutenção como a religião ${ }^{1}$, não se consegue impedir

\footnotetext{
${ }^{1} \mathrm{O}$ vocábulo "religião" tem um sentido complexo, variável e confuso, pois é um vocábulo situado, histórica, geográfica, cultural e demograficamente no seio de uma determinada comunidade linguística, que em situação particular dá sentido ao vocábulo. Entretanto, reconhecendo a existência de um emaranhado de sentidos do termo, Maduro (1983), entende religião como "uma estrutura de discursos e práticas comuns a um grupo social referentes a algumas forças (personificadas ou não, múltiplas ou unificadas) tidos pelos crentes como anteriores e superiores ao seu ambiente natural e social frente às quais os crentes expressam certa dependência (criados, governados, protegidos, ameaçados etc.) e diante dos quais se consideram obrigados a um certo comportamento em sociedade com seus semelhantes (MADURO, 1983, p.29) O autor considera qualquer fenômeno social (discurso, rito, conflito, etc.) como religioso, na medida em que tenha sido produzido no seio de práticas e discursos que conservem uma referência a forças sobrenaturais.
} 
a prática clandestina e insegura do aborto $^{2}$, que leva mulheres economicamente desprivilegiadas, em grande maioria negras, a recorrer ao aborto clandestino e ter como consequências infecções, sequelas e até morte. Mulheres de poder aquisitivo maior recorrem a serviços prestados por clínicas particulares que mantém um risco de saúde baixo.

Fica evidente então, que a criminalização do aborto além de não evitar sua realização levando à prática clandestina em condições péssimas de higiene, acentua as desigualdades de classe e contribui para aumentar a invisibilidade social desta problemática, impondo como pano de fundo, uma experiência marcada por conflitos, culpa, medo e solidão, já que poucos homens compartilham essa experiência com as mulheres (CORTÊS, 2002).

O direito a saúde sexual e reprodutiva da mulher tem se constituído em elemento fundamental dos direitos humanos discutidos em diferentes documentos elaborados nas conferências internacionais das Nações Unidas a partir da década de 1990. Com a Conferência Internacional sobre População e Desenvolvimento (CAIRO, 1994) e com a IV Conferência Mundial sobre a Mulher (BEIJING, 1995) fica instituído que os direitos sexuais e reprodutivos são essenciais para os direitos humanos. $\mathrm{O}$ aborto inseguro passa a ser reconhecido pela comunidade internacional como um grave problema de saúde pública, e faz recomendação aos governos que revisem as leis de caráter punitivo contra as mulheres que porventura passem pela vivência de um aborto ilegal, além de propiciar serviços de qualidade para tratar de complicações dele decorrente (ROCHA, 2003).

A proibição legal do aborto está longe de conseguir a diminuição da morte de mulheres e muito menos de inibir sua prática, além do que, sua criminalização tira a autonomia das mulheres, sua liberdade individual, e, ainda demonstra, o quanto a democracia brasileira está permeada por valores religiosos que tentam impor seus dogmas aos indivíduos com maior prejuízo às mulheres.

O movimento feminista, inconformado, politizou-se e desfez a relação obrigatória entre sexualidade e reprodução, considerando a descriminalização/legalização do aborto, um marco fundamental na luta por direitos reprodutivos, direitos sexuais e por uma democracia plural, que seja vivenciada por homens e mulheres.

${ }^{2}$ Aborto inseguro se define como um procedimento para interromper a gravidez não desejada,
realizado por pessoas que não possuem as habilidades necessárias ou num ambiente que nao 
cumpre os padrões médicos mínimos, ou ambos (OMS).Assim, considerando-se que a luta heterodoxa por direitos sexuais e reprodutivos tem como um de seus focos o debate em torno da descriminalização do aborto, tem-se por objetivo investigar em que medida os projetos de leis propostos por membros da bancada evangélica tem se colocado como representantes da ortodoxia social, religiosa e jurídica.

A categoria de gênero será utilizada como referencial teórico e metodológico para a construção do trabalho, pois esta abordagem faz uma ruptura com as concepções construídas a partir da biologia a respeito das diferenças entre homens e mulheres, além de ser de grande contribuição para a discussão das desigualdades e das relações de poder construídas socialmente a partir do habitus como predisposições estruturadas e estruturantes que alicerçam as relações sociais de dominação legitimadas pela religião e pelo Direito, na medida em que fundamentam a produção social de significados, pois, as representações socioculturais construídas por ambos, relativas ao masculino e feminino, fazem que seja sacramentada a desigualdade como natural.

Para elaboração deste trabalho, utilizou-se a pesquisa qualitativa privilegiando a Pesquisa Bibliográfica que contribuiu para a construção do trabalho por oferecermeios de conhecer dados já escritos por outros pesquisadores, reforçando as informações, principalmente nas questões de gênero e jurídicas relativas ao tema.

\section{A questão do aborto: um olhar necessário}

Ao longo de séculos a questão do aborto tem sido retomada e abordada de formas distintas. A criminalização do aborto perpassa por uma história que se modifica pelos diferentes sujeitos e pelas diferentes sociedades no que se refere às relações de gênero configurando atualmente como uma problemática de saúde pública e de desigualdade sexual.

O período que vai da antiguidade até o século XVIII, passando pela Grécia e Roma antigas, Idade Média e Moderna há um elemento de continuidade - o aborto é uma coisa de mulheres ${ }^{3}$, pois é a única que podia atestar a existência da gravidez e o senso comum não via no feto uma entidade autônoma, mas como parte do corpo materno. Mesmo com o judaísmo e cristianismo com oposição estruturada ao aborto entendido

\footnotetext{
${ }^{3}$ A gravidez era uma alteração do corpo feminino, um acontecimento que dizia respeito a um só sujeito: a mulher. Assim, no caso de escolha entre a mulher e o nascituro, nunca se colocaria a vida da mulher e do feto no mesmo nível, uma vez que durante séculos foi inadmissível a comparação entre um ser formado e um ainda não considerado como tal (GALEOTTI, 2007).
} 
como contrário à soberania de Deus, e conferindo ao feto uma relevância própria gestação, parto e aborto, continuam a ser coisas de mulheres, sendo o seu foro o espaço privado feminino.

A situação se transforma com a Revolução Francesa, quando o aborto passa a ter uma validade pública. Os conhecimentos desenvolvidos no século XVII tornaram possível a visualização concreta do feto, entendido agora na sua individualidade, pois as luzes ao iluminarem tudo, iluminaram também o interior do ventre feminino (GALEOTTI, 2007).

Assim, segundo Galeotti, os Estados Nacionais saídos da Revolução Francesa passam a tutelar o nascituro enquanto entidade politicamente relevante. A taxa de natalidade passa a ser importante para a força do Estado que precisava de cidadãossoldados e cidadãos-trabalhadores. Esta orientação se mantém ao longo de quase dois séculos até que no século XX alguns países dão uma nova solução ao conflito alterando suas legislações tutelando direitos e escolhas da mulher.

Até 1950, o aborto era ilegal ou severamente restrito em praticamente todos os países do mundo, mas as consequências do aborto inseguro geraram o rápido aumento do número de países que o liberalizaram ou legalizaram, principalmente os desenvolvidos.

No Brasil as práticas de aborto foram comuns em diferentes períodos da história, sendo alvo de leis, de motivos de visitas da Inquisição, de preocupações da medicina e também do setor público, fazendo com que a civilização brasileira fosse sendo construída por meio da regulamentação das condutas sexuais das mulheres (PEDRO, 2003).

É importante mencionar que o aborto na história do Brasil deve ser entendido a partir do contexto do período colonial, no qual Portugal preocupava-se com o vazio demográfico nas terras brasileiras. Para efetivar a política de ocupação, a metrópole portuguesa apoiava-se numa tripla vertente: a primeira, lutava contra as relações consensuais e concubinárias fora do controle do Estado e da Igreja Católica ${ }^{4}$. Com esta medida, impedia-se o crescimento de populações mestiças, pobres, trânsfugas, que viviam a margem do sistema mercantilista que queriam implantar no Brasil; a segunda, foi a

\footnotetext{
${ }^{4}$ Neste período, a Igreja Católica trabalhou para que fosse difundido no Brasil uma campanha de moralização das relações entre os sexos. Nesta campanha divugou-se o ideal da "santa maezinha"; a exigência de regulamentação das relações por meio do matrimônio; e pregava-se a extinção das práticas abortivas assim como do infanticídio (PEDRO, 2003,p.29).
} 
proibição de instalação de conventos de freiras desde 1606, com o objetivo de povoar as terras brasileiras. Esta medida proibia as mulheres de ter outras realizações fora da vida conjugal e familiar reduzindo-as à condição de reprodutoras; a terceira, impunha o matrimônio como mecanismo de controle da população, garantindo o aumento populacional da colônia.

Assim, o objetivo da metrópole portuguesa era a multiplicação das gentes e o aborto constituía-se numa forma de controle demográfico que não tinha o apoio nem do Estado nem da Igreja (PRIORE, 1994, p.43). Segundo a autora, o aborto, tanto no Brasil quanto em Portugal fazia parte do universo da maternidade e da feminilidade, e Igreja e Estado afinavam-se na perseguição ao ato que significava a antítese da maternidade.

A perseguição à prática do aborto inseriu-se no interior de discursos contra as ligações extramatrimoniais, divulgando-se o pressuposto de que as mulheres que abortavam, o faziam por manter ligações ilícitas ${ }^{5}$ (PEDRO, 2003, p.29),

Pelo setor público, a perseguição ao aborto foi feita através das Ordenações e posteriormente dos Códigos Penais. As ordenações Afonsinas, Manuelinas e Filipinas vigoraram no Brasil até o Código Criminal do Império em 1830. Neste Código não era prevista pena para quem praticasse o auto aborto, mas pena de um a cinco anos para o aborto provocado por terceiros. Posteriormente em 1890, houve o Código Penal Republicano, e, em 1932, as Consolidações das Leis Penais. O Código de 1890 altera a punição relativa ao auto aborto passando a penalizar de um a cinco anos a mulher que abortar voluntariamente, assim como o aborto provocado por terceiros.

Importante salientar que, diferentemente do código de 1830, o Código de 1890 foi aprovado no contexto de uma outra relação entre os gêneros, pois no Brasil ocorria a influência crescente dos conhecimentos da medicina aplicados na área da justiça. O prestígio da medicina refletiu na definição de maior punibilidade para as práticas de aborto que já vinha ocorrendo na Europa desde o final do século XVIII. Enquanto na Europa na primeira metade do século XIX, países como Inglaterra, França e Alemanha aumentavam a rigidez para as práticas abortivas, o Código Penal de 1830 era muito mais

\footnotetext{
${ }^{5}$ A "porca dos sete leitões", mito europeu e ibérico, ativo desde a idade média, e com grande aceitação em terras brasileiras, tinha a porca como representante dos apetites baixos da suja carnalidade sexual, expressa na forma como as esposas criticavam as atividades clandestinas dos maridos ressaltando as ligações extraconjugais. $\mathrm{O}$ mito trata-se da alma de uma mulher que pecou com o filho nascituro e tantos forem os abortos serão o número de leitões. Assim, Igreja e Estado iam de encontro com a mentalidade popular para combater o aborto na rejeição à mulher que
} 
quebrava o acordo com as leis da natureza (PRIORE, 1994).tolerante. A questão se inverte no Código de 1890 ao instituir leis mais rigorosas e muito mais desfavoráveis às mulheres, no momento em que, na Europa, as influências do movimento neomalthusiano fizeram com que permissivos legais fossem aprovados em relação às práticas abortivas. Além do mais, no Brasil a campanha era pelo crescimento da população preferencialmente com brancos, emergentes da corrente imigratória vinda da Europa (PEDRO, 2003, p. 30-2).

Fica evidente o quão forte foi a influência portuguesa na construção da sociedade brasileira, tanto na construção da lei que criminalizava o aborto, quanto dos dogmas religiosos, que dão manutenção à punibilidade das mulheres.

Nas legislações atuais há em relação ao aborto três tendências: uma restritiva, que pode ser notada no Código Penal brasileiro; uma permissiva que, em diferentes casos consente a prática abortiva (como idade avançada da mulher, morte ou incapacidade do pai, mulher não casada, possível deformação do feto, incapacidade física ou psíquica da mulher, prole numerosa); e um terceiro grupo de leis que confia a decisão à mulher e permite que o médico decida quanto ao aborto (COSTA JR., 1988, p.31).

As normas legais que vigoram atualmente no Brasil foram formuladas durante o período ditatorial do Estado Novo, resultando no Código Penal de 07-12-40 (Decreto Lei, 2849). Em 1977 foram realizadas algumas alterações (Lei 6416, de 24-05-77), assim como em 1984 com a Lei 7209, de 11-07-84, com uma reformulação da sua parte geral. Mas as referidas reformulações não alteraram as partes vinculadas a criminalização do aborto.

O aborto no atual Código Penal está classificado entre os crimes contra a vida que é subclasse dos crimes contra pessoa e sujeito a julgamento pelo Tribunal do Júrí ${ }^{6}$. Em 1941, a Lei de Contravenções Penais reforça a ilicitude do aborto em seu artigo 20: "anunciar processo, substância ou objeto destinado a provocar aborto" com pena de multa. A redação deste artigo incluía até 1979 a propaganda e fabrico de métodos contraceptivos (ROCHA,2003). Para Àvila esta lei foi elaborada sob uma forte influência de governos nazifascistas que fomentavam em seus países uma política natalista (ÀVILA, 1993, p. 388).

\footnotetext{
${ }^{6} \mathrm{O}$ Tribunal do Júri é instituído na realidade brasileira para os julgamentos dos crimes dolosos contra a vida. Trata-se de um júri popular composto por um juiz togado e 21 jurados dos quais são sorteados 7 para integrar o conselho de sentença. Sua previsibilidade no art. $5^{\circ}$ inciso XXXVIII da Constituição Federal se mantém em constante tensão dadas suas características de um lado elitista e de outro altamente dificultoso de eficácia.
} 
No Brasil, o aborto está descrito na lei penal como crime, sendo possível notar que há permissivos legais para a prática do aborto com os incisos I e II do artigo 128 do código de 1940. Na primeira legislatura que sucedeu à abertura do Congresso Nacional em 1949, houve manifestações contrárias aos dois permissivos legais por parte de setores da Igreja Católica com o Projeto Lei de Monsenhor Arruda Câmara (PDC/PE) com alegações baseadas na moralidade cristã com a retórica de que o aborto seria um atentado contra a vida humana, que já existia desde a concepção. Em 1995, a proposta de Emenda Constitucional n.25/95 de Severino Cavalcanti tinha por objetivo proibir o aborto em todos os casos (ROCHA, 1996).

\section{Projetos de lei como proposta de reestruturação da ortodoxia}

A autoridade dos que criaram as normas jurídicas e religiosas ao longo da história, por deterem o poder, designaram regras de comportamento sem necessidade de justificação. Nesse caso, pode-se perceber que "a força da ordem masculina se evidencia no fato de que ela dispensa justificação" (BOURDIEU, 1999, p.18). A especificidade do discurso de autoridade se encontra no fato de que é preciso que seja reconhecido, para que surja o efeito desejado (BOURDIEU, 1998, p.91). Nesse caso, legislador e líder religioso tem como aliada a força da dominação masculina que, por meio da violência simbólica, faz que o dominado aceite a relação de dominação como natural. Lembrando que, a forma como ambos pensam suas elaborações é parte da estrutura de dominação, pois todo ato de conhecimento do sujeito cognoscente é um ato de desconhecimento da dominação (BOURDIEU, 1999).

Por intermédio da norma jurídica, o discurso da lei atua sobre as estruturas históricas do inconsciente garantindo a perpetuação das diferenças entre os gêneros. Condição que só seria mudada a partir "de uma análise das transformações dos mecanismos e das instituições encarregadas de garantir a perpetuação da ordem dos gêneros" (BOURDIEU, 1999, p.102-3).

Para Bourdieu (1999) as relações de gênero são relações de dominação e em relação à esta lógica, deve-se procurar apreender o modo como foi sendo construída a legitimação da sociedade em termos de gênero, e buscar uma forma de transformação a partir de um trabalho de socioanálise do inconsciente androcêntrico capaz de operar a objetivação das categorias desse inconsciente” (BOURDIEU, 1999, p. 13). Para o autor, 
[...] a sociedade existe sob duas formas inseparáveis: de um lado as instituições que podem revestir a forma de coisas físicas, monumentos, livros, instrumentos, etc.; do outro as disposições adquiridas, as maneiras duradouras de ser ou fazer que encarnam em corpos (e a que eu chamo os habitus) ${ }^{7}$. (BOURDIEU, 2003, p. 33)

O habitus é o que se adquiriu, mas encarnou de modo duradouro no corpo sob a forma de disposições permanentes. A interiorização de valores sociais que se inscrevem no corpo garante a adequação entre as ações do sujeito e a sociedade apresentando-se o habitus como social e individual. O habitus é um sistema de disposições adquiridas na socialização que vai aumentando com as novas experiências sociais predispostas a funcionar como estruturas estruturantes, ou seja, como princípios geradores e organizadores de práticas e representações. O habitus é uma noção dinâmica sendo o agente social criativo - um agente em ação.

[...] é um produto dos condicionamentos que tende a reproduzir a lógica objetiva dos condicionamentos mas fazendo-a sofrer uma transformação; é uma espécie de máquina transformadora que faz com que "reproduzamos" as condições sociais da nossa própria produção, mas de uma maneira relativamente imprevisível, de uma maneira tal que não podemos passar simples e mecanicamente do conhecimento das condições de produção ao conhecimento dos produtos. (BOURDIEU, 2003, p. 140)

Ao discutir o conceito de habitus no processo de subordinação da mulher, afirma o autor ser a violência simbólica o mecanismo utilizado para que a dominação masculina se dê num processo lento e organizado a partir de categorias androcêntricas, que podem ser percebidas pelo modo de pensar, falar e sentir inscritos nos corpos e mentes dos indivíduos. As diferenças anatômicas percebidas nos corpos de homens e mulheres são uma das divisões utilizadas para que os poderes entre ambos se deem de maneira desigual tendo o princípio masculino como parâmetro para todas as coisas e

\footnotetext{
${ }^{7}$ Para construir a noção de habitus Bourdieu retoma a noção aristotélica de hexis, que foi posteriormente convertida em habitus pela escolástica, privilegiando um aprendizado adquirido no passado.
} 
contribuindo com o aumento do capital simbólico em poder dos homens (BOURDIEU, 1999).

O princípio da visão dominante nas relações de gênero não se reduz a "uma simples representação mental, uma fantasia ("ideias na cabeça"), uma "ideologia", e sim um sistema de estruturas duradouramente inscritas nas coisas e nos corpos" (BOURDIEU, 1999, p.53-4), pois estão incorporados nos habitus alicerçando as relações de dominação. O que pode ser visto nas relações desiguais de trabalho, no acesso a determinadas carreiras, nas legislações, nas relações econômicas, nas instituições de educação, familiares, assim como a maneira de uso do corpo que é feita diferentemente por homens e mulheres.

Fazer uma reflexão sobre o aborto a partir da perspectiva das relações de gênero pede o reconhecimento dos poderes desiguais entre homens e mulheres, a começar pela forma como os indivíduos vivenciam as representações que os orientam na vida social, assim como especificamente na construção social sobre a maternidade.

A interdição ao aborto evidencia o poder referente aos direitos sexuais e reprodutivos postulados diferentemente para homens e mulheres nos espaços sociais. $\mathrm{Na}$ questão da maternidade deve-se pensá-la não somente como um caráter natural-biológico, mas sociológico e antropológico para se compreender suas múltiplas faces (SCAVONE, 2004, p.143). Para a autora, além da responsabilidade feminina na reprodução humana desde a responsabilidade pelos corpos gerados na gravidez, no parto, na amamentação e na vida da criança, há a responsabilidade do controle da concepção pelos métodos contraceptivos serem majoritariamente para mulheres. Importante lembrar que, a contracepção e o aborto são a face da negação da maternidade como possibilidade de dizer não, embora um não difícil para as mulheres à maternidade como fato biológico irreversível (SCAVONE, 2004, p.144).

Pode-se notar que historicamente a partir de métodos contraceptivos naturais, do aborto e do infanticídio (PEDRO, 2003; KITZINGER, 1978), as mulheres negaram a maternidade como imposição natural e como fator determinante para a construção do ser mulher (SCAVONE, 2004).

A maternidade e o aborto e suas significações segundo Cortês (2002), enquadram-se em oposições binárias, em dicotomias, pois de um lado a maternidade reveste-se de um habitus baseado em representação positiva ligada a ideia do bem e a sexualidade regrada e moralizada, e, por outro, o aborto ligado ao mal, ao pecado, ao 
crime e a uma sexualidade desregrada e condenável.Considerando-se que as relações de gênero são relações de dominação nas quais a proibição ao aborto aparece na instituição jurídica como uma forma de violência simbólica, Bourdieu (1999, p. 7), que faz a submissão não ser visível para as suas próprias vítimas, que, por muitas vezes acabam assumindo uma atitude encantada com os dominadores, ou seja, as mulheres neste caso acabam reproduzindo um discurso construído pela visão dominante como se fosse o seu. Neste caso, o discurso jurídico que tem por objetivo primeiro regulamentar a vida em sociedade, faz com que seja aceito sem questionamento o texto legal, no qual, a assimetria entre homens e mulheres fica ressaltada, pois legitima uma cidadania restringida, pois se avança em alguns direitos como, por exemplo, algumas mudanças constitucionais de 1988, como também o Código Civil de 2002, mas mantém ou colocam-se impedimentos na conquista de outros, como é o caso da manutenção da criminalização do aborto no Código Penal Brasileiro representando a partir do não direito ao corpo, uma cidadania que não integra o indivíduo por inteiro.

Diante das questões legais impostas pelo campo jurídico, muitas mulheres tornam-se também portadoras do habitus adquirido junto a ele dando continuidade à aceitação do texto legal sem questionamento e acolhendo a criminalização do aborto como uma questão jurídica e não como um direito da mulher a escolha de uma maternidade não imposta.

Complementar a noção de habitus, o conceito de campo é relativo a um espaço de forças sociais no qual se manifestam as relações de poder. Assim, o campo é entendido como um "sistema de desvios de níveis diferentes e nada nem nas instituições ou nos agentes nem nos atos ou nos discursos que eles produzem, tem sentido se não relacionalmente, por meio do jogo das oposições e das distinções” (BOURDIEU, 2000, p. 179).

Cada campo possui características que o diferem dos outros tendo seus interesses específicos e sua regulamentação própria. O campo social é delimitado, tem sua conjuntura, é um espaço estruturado, espaço de forças que em todas as relações sociais está embutida as relações de poder, entendidas como capital econômico, simbólico, cultural e social. Assim todo campo é um espaço de lutas pela apropriação do capital que em cada circunstância mostra em determinada relação de força o seu objetivo. Para Bourdieu, 
A estrutura do campo é um estado da relação de força entre os agentes ou as instituições envolvidas na luta ou, se se preferir, da distribuição do capital específico que, acumulado no decorrer das lutas anteriores, orienta as estratégias posteriores. Esta estrutura, que está no princípio das estratégias destinadas a transformá-la, está ela própria sempre em jogo: as lutas cujo lugar é o campo têm por parada em jogo o monopólio da violência legítima (autoridade específica) que é característica do campo considerado, quer dizer, em última análise, a conservação ou a subversão da estrutura da distribuição do capital específico. (BOURDIEU, 2003, p. 120)

O campo nesta concepção é dividido em dois pólos significativos: de um lado, o pólo dominante que com capital específico inclina-se para estratégias de conservação que correspondem a defesa da ortodoxia; e de outro, o pólo dominado com menor poder de capital volta-se para as práticas heterodoxas pois, procura manifestar sua insatisfação por meio de estratégias de subversão.

Assim, a estrutura do campo está sempre em luta, pois os agentes sociais ao adotar estratégias de conservação ou de subversão determinam uma nova distribuição do capital dentro do campo. Para se compreender a lógica social de um campo, é preciso apreender o que faz a necessidade específica da crença que lhe dá suporte, do jogo de linguagem que se joga, das coisas materiais e simbólicas que estão em jogo (BOURDIEU, 2000, p. 69)

Na questão do aborto vários campos concorrem para a manutenção de valores específicos para manutenção de sua interdição, mas nos campos jurídico e religioso estão precisamente as leis e os dogmas que são sempre lembrados nas situações em que o tema aborto é mencionado. Tanto o Direito como a Religião são instituições sociais que estruturam as relações de poder, contribuindo para a manutenção da assimetria entre mulheres e homens. No momento em que essas instituições se unem potencializa-se a cada uma o capital simbólico que as sustentam. Assim, Projetos de lei propostos pela bancada evangélica encontra-se campo fértil para que a ortodoxia se reorganize e possibilite o impedimento de novos direitos das mulheres na medida em que retira os já conquistados.

De acordo com o Departamento Intersindical de Assessoria Parlamentar (DIAP), que teve por base os dados disponíveis no portal do Tribunal Superior Eleitoral 
(TSE), a bancada evangélica no Congresso Nacional a partir da eleição de 2018 está composta por 91 congressistas, tendo portanto 13 parlamentares a mais que a legislatura anterior. Eleitos 84 para a Câmara dos Deputados sendo nove a mais do que na última legislatura. No Senado também houve um grande aumento pois os evangélicos eram três e, em 2019, serão sete parlamentares.

A Bancada Evangélica é composta por parlamentares de diversos partidos, que são declaradamente evangélicos e tem especialmente por objetivo discutir questões como a igualdade de gênero, a questão do aborto e a legalização do casamento de pessoas do mesmo sexo a partir de uma perspectiva de valores religiosos que entendem ser a representação de suas verdades, sendo contra toda e qualquer proposta minimamente progressista que viabilizem a igualdade de gênero, o casamento de pessoas do mesmo sexo e a descriminalização do aborto. A bancada também se posiciona de forma contrária a adoção de crianças por casais homoafetivos, assim como a possibilidade de criminalização da homofobia. Pode-se perceber que alguns projetos de leis propostos por membros da bancada evangélica tem se colocado como representantes da ortodoxia social, religiosa e jurídica.

O Projeto de lei 5069/2013 de autoria de Eduardo Cunha tipifica comocrime contra a vida o anúncio de meio abortivo e prevê penas específicas para quem induz a gestante à prática de aborto. Torna crime o anuncio de métodos abortivos e prestação de auxílio ao aborto, especialmente por profissionais de saúde. Dificulta assim, o acesso ao aborto já legalizado e ao atendimento pela Lei 12.845/2013 que dispõe sobre o atendimento obrigatório e integral de pessoas em situação de violência sexual. O Projeto de lei 6033/2013de Eduardo Cunha revoga a Lei $n^{\circ} 12.845$, de $1^{\circ}$ de agosto de 2013 referente ao atendimento a mulher vítima de estupro. Também de Eduardo Cunha é o Projeto de Lei 1545/2011 que prevê Pena de reclusão de seis a vinte anos para médico que realiza o aborto e ainda será proibido definitivamente do exercício da profissão.

Luis Bassuma propõe o Projeto de lei 1413/2007 que proíbe a distribuição, a recomendação pelo SUS e a comercialização pelas farmácias de método de anticoncepção de emergência - Pílula do dia seguinte.

O Projeto de Lei 478/2007 de Luiz Bassuma e Miguel Martini dispõe sobre o Estatuto do Nascituro. O projeto aponta que a vida começa na concepção e estipula o pagamento de uma bolsa em dinheiro para as mulheres vítimas de estupro que optarem por não fazer o aborto.Art. 13. O nascituro concebido em um ato de violência sexual 
não sofrerá qualquer discriminação ou restrição de direitos, assegurando- lhe, ainda, os seguintes: I - direito prioritário à assistência pré-natal, com acompanhamento psicológico da gestante; II - direito a pensão alimentícia equivalente a 1 (um) salário mínimo, até que complete dezoito anos; III - direito prioritário à adoção, caso a mãe não queira assumir a criança após o nascimento.

Parágrafo único. Se for identificado o genitor, será ele o responsável pela pensão alimentícia a que se refere o inciso II deste artigo; se não for identificado, ou se for insolvente, a obrigação recairá sobre o Estado.

O Projeto de Lei 4396/2016 de Anderson Ferreira altera dispositivo do Código Penal (Decreto Lei no 2.848, de 7 de dezembro de 1940) para prever aumento de pena no caso de aborto cometido em razão da microcefalia ou anomalia do feto.

De Rômulo Gouveia é o Projeto de Lei acrescenta dispositivo à Lei no 8.069, de 13 de julho de 1990, para tornar obrigatória a comunicação, pelos estabelecimentos de saúde, de aborto ou de sua tentativa.

De Marco Feliciano é o Projeto de Lei 5617/2016 que Institui o Dia Nacional de Conscientização Antiaborto. O Congresso Nacional decreta: Art. $1^{\circ}$. Esta Lei institui o Dia Nacional de Conscientização Antiaborto. Art. $2^{\circ}$ Fica instituído o Dia Nacional de Conscientização Antiaborto, a ser comemorado, anualmente, na segunda sexta-feira do mês de maio.

Os referidos projetos nos possibilitam a percepção de que o campo jurídico por normatizar padrões e estabelecer condutas para a vida reprodutiva das mulheres com a proibição do aborto, juntamente com a colaboração do campo religioso, representado pela bancada evangélica por estabelecer condutas morais inquestionáveis segundo seus próprios dogmas, funcionam como mecanismo de sustentação para (re)construção e manutenção da dominação uma vez que a prática abortiva não deixa de ocorrer pelas interdições criadas por ambos gerando uma clara injustiça de gênero, raça e classe.

O campo jurídico e religioso mostram-se como terrenos férteis para o desenvolvimento, afirmação e perpetuação de valores androcêntricos, no momento em que o campo religioso, entra em espaços do campo jurídico, efetuando-se a partir de valores e normas interiorizadas por instrumentos legais. Neste momento há uma 
retroalimentação pelos campos na medida em que um se beneficia do discurso do outro para a manutenção da ortodoxia de ambos.

Por meio de estratégias de subversão, numa contínua proposta heterodoxa, o movimento feminista em cada momento utilizam diferentes mecanismos para desconstruir a estrutura de dominação masculina numa tentativa de desmascarar os interesses em jogo. Pode-se perceber que o movimento tem buscado elementos para desconstruir e reconstruir os olhares sobre o direito das mulheres ao seu próprio corpo, pois, as estruturas das relações que constituem o campo religioso tem um mecanismo externo de legitimação da ordem estabelecida na medida em que a manutenção da ordem simbólica contribui de forma direta para a manutenção da ordem política e a subversão desta ordem só consegue atingi-la no momento em que se faz uma subversão política desta ordem (BOURDIEU,1987, p.69).

Temos que lembrar que a construção do corpus legal ocorre no campo jurídico e que segundo Bourdieu este campo "é o lugar de concorrência pelo monopólio do direito de dizer o direito, quer dizer a boa distribuição ou a boa ordem (nomos) na qual defrontam agentes investidos de competência ao mesmo tempo social e técnico" (Bourdieu, 2000, p. 212). O campo jurídico é o lugar onde o poder define-se numa relação determinada entre os que exercem o poder e os que lhe são sujeitos na própria estrutura do campo em que se produz e se reproduz a crença. Neste caso "o que faz o poder das palavras e das palavras de ordem, poder de manter a ordem ou de a subverter, é a crença na legitimidade das palavras e daquele que as pronuncia, crença cuja produção não é da competência das palavras" (BOURDIEU, 2000, p. 15). O não questionamento do texto legal acentua a naturalização da desigualdade fazendo com que a ausência de uma relação dialética de oposição, mascare o problema e desempodere qualquer possibilidade de uma ação política do dominado.

Bourdieu discute sobre a importância da religião nos processos sociais como um espaço comparável ao mercado segundo lógicas singulares e próprias com seu comércio de símbolos, denominando-os de campo religioso (BOURDIEU, 1987, p. 57). Este campo funciona como princípio de estruturação que constrói a experiência na medida em que a expressa assumindo uma função prática e política de legitimação do arbitrário, fazendo com que o habitus religioso mantenha criando e recriando pensamentos, percepções e ações segundo as normas de uma representação religiosa do mundo natural e sobrenatural (BOURDIEU, 1987, p. 45-6). Questão que pode ser percebida ao analisar 
Projetos de Lei propostos por membros da bancada evangélica, assim como textos jurídicos nos quais o poder religioso estabelece parâmetros para a construção da lei. Numa perspectiva representativa da ortodoxia social, religiosa e jurídica no Brasil.

\section{Conclusões}

Entendemos que a política feminista foi/é fator determinante para as lutas, mudanças e conquistas relativas ao direito à saúde reprodutiva, pela desconstrução de um habitus que naturaliza as diferenças, precisamente na questão do aborto. Por intermédio de estratégias de subversão, o movimento feminista em cada momento utilizam diferentes mecanismos para desconstruir a estrutura de dominação masculina numa tentativa de desmascarar os interesses em jogo.

O campo jurídico por normatizar padrões e estabelecer condutas para a vida reprodutiva das mulheres com a proibição do aborto, juntamente com a colaboração do campo religioso, por estabelecer condutas morais inquestionáveis segundo seus próprios dogmas, funcionam como mecanismo de sustentação para (re)construção e manutenção da dominação uma vez que a prática abortiva não deixa de ocorrer pelas interdições criadas por ambos gerando uma clara injustiça de gênero/classe.

Para que a conquista da cidadania e os direitos humanos das mulheres alcancem uma implantação real, e os direitos adquiridos gerem a transformação na organização da vida, sem que ocorra um equívoco entre o início da norma e sua efetivação a partir de uma cidadania integral, entende-se ser necessário que haja a efetividade da laicidade do Estado para que se diminua a distância entre leis e a realidade que vive as mulheres.

Para isso necessário se faz a conscientização dos direitos conquistados por toda a sociedade na busca de uma democracia sustentável para uma cidadania plena, que ultrapasse o reconhecimento de um direito objetivado em texto legal, e busque sim, saber utilizá-lo como um direito subjetivo. A obtenção desses direitos deve, necessariamente, subverter a lógica da exclusão da cidadania com a apropriação de novos direitos, enquanto reconfigura os já existentes.

\section{Referências Bibliográficas}


ÁVILA, Maria Betânia. Cidadania, direitos humanos e direitos das mulheres. In: BRUSCHINI, Cristina \& UNBEHAUM, Sandra G. (org) Gênero, democracia e sociedade brasileira. São Paulo: Fundação Carlos Chagas/Editora 34, 2002.

Feminismo y cidadania: la producción de nuevos derechos. In: SCAVONE,

Lucila. (comp) Gênero y salud reproductiva em América Latina. $1^{\mathrm{a}}$ ed. Cartago: Libro Universitário Regional, 1999.

. Modernidade e cidadania reprodutiva. In: Revista Estudos Feministas, Ano $1,1993$.

BOURDIEU, Pierre. In: ORTIZ, Renato. (org). Sociologia. Coleção grandes cientistas sociais. São Paulo: Editora Ática, 1994

A dominação masculina. Rio de Janeiro: Bertrand Brasil, 1999.

O poder simbólico. Rio de Janeiro: Ed. Bertrand Brasil, 2000.

Questões de sociologia. Lisboa: Fim de século, 2003.

Costa Jr, Paulo José da. Comentários ao Código Penal. São Paulo: Saraiva, 1988.

CORTÊS, Gisele Rocha. O discurso médico sobre o aborto provocado. Araraquara: Unesp, 2002. Dissertação de mestrado.

FOUGUERA, Pilar. La equidad de gênero en el marco internacional y europeo. In: Del Vale, Teresa. Mujeres, globalización y derechos humanos. Madrid: Edições Cátedra, 2006.

GALEOTTI, Giulia. História do aborto. Lisboa: Edições 70, 2007.

JELIN, Elizabeth. Mulheres e direitos humanos. Estudos Feministas. Vol 2, n.3 Rio de Janeiro: 1994. p.117-49.

KITZINGER, Silvia. Mães: um estudo antropológico da maternidade. São Paulo: Martins Fontes, 1978.

MADURO, Otto. Religião e Luta de Classes. Petrópolis: Vozes, 1983.

PEDRO, Joana Maria. Aborto e infanticídio: práticas muito antigas. In: PEDRO, Joana Maria (Org). Praticas proibidas: práticas costumeiras de aborto e infanticídio no século XX. Florianópolis: Cidade Futura, 2003.

PRIORE, Mary Del. A árvore e o fruto: um breve ensaio histórico sobre o aborto. Bioética. Brasília: Conselho Federal de Medicina, 1994.

Radiografia do Novo Congresso: Legislatura 2019-2023 / Departamento Intersindical de Assessoria Parlamentar. - Brasília, DF : DIAP, 2018. 
ROCHA, Maria Isabel Baltar da. A questão do aborto no Brasil: o debate no congresso. In: Revistas Estudos Feministas, vol. 4, n. 2. São Paulo: 1996.

A discussão política sobre o aborto no Brasil: uma síntese. In: Revista Brasileira de Estudos sobre a População. São Paulo, v.23, n.2, 2006.

ROCHA, Maria Isabel Baltar da \& Neto, Jorge Andalafat. A questão do aborto: aspectos clínicos, legislativos e políticos. In: BERQUÓ, Elza (org). Sexo e vida: panorama da saúde reprodutiva no Brasil. Campinas: Editora da Unicamp, 2003.

SCAVONE, Lucila. Recursos conceituais: feminismo e ciências sociais. IN:

(Org.) Tecnologias reprodutivas: gênero e ciência. São Paulo: Editora Universidade Estadual Paulista, 1996.

Anticoncepción, aborto y tecnologias conceptivas: entre la salud, la ética y los derechos. In: Gênero y salud reproductiva em América Latina. $1^{a}$ ed. Cartago: Libro Universitário Regional, 1999.

Dar a vida e cuidar da vida: feminismo e ciências sociais. São Paulo: Editora Unesp, 2004.

\& Cortês, Gisele. Entre o subjetivo e o social: implicações sociológicas do aborto. In: SCAVONE, Lucila \& BATISTA, Luís Eduardo. Pesquisas de gênero: entre o público e o privado. Araraquara: Laboratório Editorial, 2000.

SCOTT, Joan. Gênero como categoria útil de análise histórica. In: Educação e Realidade. v.16, p.5-22, 1990. . História das mulheres. In: Burke, Peter (org). A escrita da história. São Paulo: Edunesp, 1996.

. A cidadã paradoxal: as feministas francesas e os direitos do homem.

Florianópolis: Editora Mulheres, 2002. 